\title{
MACA: DEL ALIMENTO PERDIDO DE LOS INCAS AL MILAGROS DE LOS ANDES. ESTUDIO DE SEGURIDAD ALIMENTARIA Y NUTRICIONAL
}

\author{
Gustavo F. Gonzales ${ }^{1}$
}

El estudio ha sido diseñado para determinar el estado de salud en una población en los Andes centrales del Perú (Carhuamayo, $4100 \mathrm{~m}$ ) que tradicionalmente consume maca comparado con aquella del mismo lugar que no consume maca. El estudio consiste en aplicar una encuesta sobre consumo de maca, aspectos sociodemográficos, de salud, y de fracturas en varones y mujeres de 3575 años de edad. A una submuestra se ha evaluado el perfil hepático, renal, y de hemoglobina. El 80\% de los pobladores de Carhuamayo consumen maca. El 85\% de esta población lo usa por motivos nutricionales. Se consume desde la niñez y principalmente cuando el hipocótilo es deshidratado naturalmente. El consumo es principalmente en forma de jugo y la variedad de consumo es una mezcla de colores. El consumo de maca se asocia a mejores puntajes de estado de salud, menores tasas de fracturas y menores puntajes de signos y síntomas de mal de montaña crónico. Se asocia igualmente al consumo de maca un menor Indice de Masa Corporal, y menor presión arterial sistólica. La función hepática, renal, el perfil lipídico y la glicemia se mantienen en lo normal. En conclusión, el consumo de maca como alimento es seguro.

Palabras-clave: maca, seguridad alimentaria, alimento funcional, Andes centrales, ciencia y tradición

\section{MACA: FROM THE LOST CROP OF THE INCAS TO THE MIRACLE OF THE ANDES. A FOOD SECURITY STUDY}

This study has been designed to determine the health status in a population from the Peruvian central Andes (Carhuamayo, 4100 $\mathrm{m})$ which traditionally consuming maca and compared with a population from the same place which does not consume maca. This study is based in a survey about maca consumption, sociodemographic aspects, health status, and fractures in men and women aged 35-75 years old. In a sub-sample was assessed the hepatic and kidney functions and hemoglobin values. From the sample studied, $80 \%$ consumed maca. The $85 \%$ of them, consume maca by nutritional purpose. Maca is used since childhood and mainly after hypocotyls is naturally dried. The consumption is mainly as juices, and the variety that they consumes are a mixture of different colors of the hypocotyls. Maca consumption is associated to higher score in health status, lower rate of fractures, lower scores of sign and symptoms of chronic mountain sickness. In addition, maca consumption is associated to low body mass index and low systolic blood pressure. Hepatic and kidney function, lipidic profile, and glycemia were normal in the population consuming maca. In conclusion, consumption of maca as food is safety.

Key words: maca, food security, functional food, mid Andes, tradition and science

\footnotetext{
${ }^{1}$ Departamento de Ciencias Biológicas y Fisiológicas, Facultad de Ciencias y Filosofía, Universidad Peruana Cayetano Heredia.Av. Honorio Delgado 430. Lima 31, Peru.E-mail: gustavo.gonzales@upch.pe
} 


\section{Introduccion}

En las últimas décadas se ha incrementado a nivel mundial el uso de plantas medicinales calculándose las ventas para 2002 en 20 billones de dólares mayormente en los países de Europa, Asia y Norte América [1]. La búsqueda de alimentos saludables y funcionales (nutracéuticos) ha coincidido con una mayor demanda para que la seguridad alimentaria sea científicamente confirmada. Se ha estimado que hay 250,000 plantas en el mundo.

El Perú, uno de los países de mayor biodiversidad en plantas en el mundo posee alrededor de 25,000 especies de las cuales un 30\% son endémicas. Es el quinto país en el mundo en número de especies; primero en número de especies de plantas de propiedades conocidas y que son utilizadas por la población (4,400 especies); y el primero en especies domesticadas nativas (128). A pesar de esta riqueza en especies botánicas, el Perú tiene lugares donde se asientan poblaciones humanas en condiciones ambientales y climatológicas adversas. La zona de la Puna sobre los 4000 metros de altura se caracteriza por una baja presión barométrica, grandes heladas, lluvias, vientos, y alta radiación solar y cósmica, donde prácticamente es imposible el crecimiento de planta alguna para el sustento humano. Esto ya fue evidenciado por los españoles cronistas de la Conquista del Perú en los Siglos XVI y XVII [2,3]. La población humana que radica en esas zonas de gran altitud se constituye en la más pobre del país. Así tenemos las poblaciones de Junín, Óndores, Carhuamayo, Huayre, Ulcumayo en el Departamento de Junín y Ninacaca en el Departamento de Pasco en los Andes centrales del Perú. Toda esta zona se ubica en lo que se denomina la "meseta de Bombón".

En estos lugares tan inhóspitos donde reside población humana, la alimentación se ha basado en la ganadería y algunas plantas que se han logrado adaptar a este ecosistema y se permite su cultivo. Es posible que la maca haya sido domesticada en el Perú desde el año 700 a.C. en San Blas, Junín (actualmente conocido como Óndores, Junín) entre los periodos Formativo Medio y Superior como lo describe Matos en $1975{ }^{[4]}$ y que su área de producción y consumo haya sido delimitada a diversas zonas entre las cuales tenemos a Chinchaycocha, Mantaro y Castrovirreyna [5].

La primera publicación sobre la maca y sus propiedades fue realizada por el Jesuita español Bernabé Cobo en su libro "Historia del Nuevo Mundo". Bernabé Cobo viajó por casi todo el Perú de entonces (Siglo XVII) y describió el acontecer y sus vivencias en cada uno de los lugares que visitó. Fue muy prolijo al describir la flora y fauna de diversas zonas del país. Su principal observación sobre la maca fue que ésta llega a crecer en áreas más frías y agrestes de la sierra donde ninguna otra planta puede crecer ${ }^{22}$. Se debe a Cobo también el haber identificado que la maca solo crece en la Diócesis de Chinchaycocha, lo que ahora corresponde a la meseta del Bombón. Cobo en 1653 no solo describe la particularidad de que en estas zonas alto-andinas de Chinchaycocha crece la maca sino que nos refiere sobre sus propiedades nutritivas y su capacidad para mejorar la fertilidad. Las evidencias históricas apuntan a un cultivo focalizado en la zona de los Andes centrales particularmente de la Meseta del Bombón [2,6]. La mayor producción de maca en la actualidad sigue focalizada en los Andes centrales. En las crónicas también se describe que en 1549 Juan Tello de Sotomayor, Encomendero de Chinchaycocha solicitaba el pago de tributos entre otros con maca. Esto evidencia el valor que tenía esta planta en la zona y en la época ${ }^{[4]}$.

El botánico español Hipólito Ruiz quien visitó Perú entre 1777-1788 reporta que las áreas de producción y consumo de la maca son Carhuamayo, Pampas de los Reyes (actualmente distritos de Carhuamayo y Óndores en el Departamento de Junín), Ninacaca y su vecindad (actualmente en el Departamento de Pasco). Todos estos poblados se ubican por encima de los 4000 metros de altura. El botánico refiere que por razones del intenso frío de la zona no crece ninguna planta que se cultiva excepto unas raíces denominadas por los nativos como "maccas". Corresponde a este botánico la referencia que le hacen los naturales de que después de ser hervidas y consumidas mejora la fertilidad en las mujeres. Por esa razón muchas mujeres que no pueden tener hijos utilizan esta planta con el propósito de tratar su infertilidad (página 63 del libro de Hipólito Ruiz). Aunque Hipólito Ruiz no pudo comprobar esta propiedad por el poco tiempo que estuvo en la zona, menciona sin embargo, que si es cierto que la maca es estimulante cuando se consume en cantidades [ $[$ ].

En 1857, Mariano Eduardo de Rivero y Ustariz [7] menciona el aspecto de higo que tiene la maca, y que es sumamente dulce y se conserva por algunos años, sin ninguna alteración. Refiere que para ello es necesaria que la maca fresca luego de ser cosechada sea expuesta por un número de días al sol y al frío, para que no sufra ninguna fermentación, y después se guarda en un cuarto que no tenga humedad. También hace mención que los pobladores lo usan porque mejora la fertilidad. 
En 1961 se realiza la primera experiencia científica tratando de confirmar las propiedades biológicas de la maca sobre el proceso reproductivo [8]. En 1989, el Consejo Nacional de Investigación de los Estados Unidos etiquetó a la maca como "el alimento perdido de los Incas" [9]. En 1994, el III Censo nacional agropecuario desarrollado por el Instituto Nacional de Estadística e Informática (INEI) del Perú reveló que tan sólo 556 Has se dedicaba al cultivo de maca. Después de que la producción de maca estuvo en sus niveles más bajos en 1994 donde llegó a 97.37 TM, debido a la demanda local e internacional, el cultivo se expandió llegando a 2,848.68 TM en el 2000 y de lo que se proyectaba a 6,790.64 TM para 2010, se ha superado largamente el 2005 con las 20,263.45 TM. La importancia de esta planta ha traspasado las fronteras de tal manera que se consume en diferentes partes del mundo. Datos estadísticos sobre las exportaciones de maca, ha demostrado que las ventas al exterior se han ido incrementando cada año a partir del año 2001.

La maca es procesada en diferentes formas y se vende como harina pulverizada, gelatinizada, o extractos acuosos o hidroalcohólicos. Estos productos son a su vez procesados en cápsulas, tabletas, sachets, extractos líquidos, entre otros ${ }^{[4,10]}$.

La maca se presenta en diferentes variedades caracterizadas por el color de los hipocótilos. Estos colores van del blanco al negro [1]. En la actualidad existen varios estudios experimentales que demuestran las diferentes propiedades biológicas de la maca. Así se han demostrado efectos biológicos diferentes para las diferentes variedades de la maca; así la maca negra entre las otras variedades es la que aumenta más el número y la movilidad de espermatozoides en ratas y ratones [11-15]. Además un estudio hecho en cuatro modelos experimentales diferentes en ratones, ha demostrado que la maca negra mejora la memoria y el aprendizaje [16,17]. Recientemente se ha demostrado su efecto en retardar la aparición de la fatiga por el nado forzado en ratones (Gonzales, no publicado).

La maca roja, por el contrario, revierte en ratas y ratones la hiperplasia benigna de próstata, inducida por el enantato de testosterona [15,18-20] además de la osteoporosis inducida por la ovariectomía en ratas. En ambos casos los efectos son mejores que los tratamientos estándar como el finasteride, en el caso de la hiperplasia de próstata, donde también se altera la función de las vesículas seminales; y el estradiol para la osteoporosis donde se observa que aumenta el peso del útero, un efecto no deseado para el tratamiento con estrógenos.
Estas variadas propiedades biológicas ha motivado un creciente interés por el uso de la maca en diferentes partes del mundo. En el Perú, la maca es consumida ya no solamente en las zonas de los Andes centrales, donde se produce, sino que hay un uso diseminado en todo el país [21]. El uso en el extranjero al aumentar su consumo genera cierta preocupación sobre la seguridad de su uso. Así, la Agencia Francesa de Seguridad de los Alimentos [22] (Afssa- no 2008-SA-0011) y el Instituto Federal Alemán de Evaluación de Riesgos (BfR no 024/2007) han procedido a evaluar los efectos de la maca en suplementos nutricionales y otros comestibles sobre la salud. Algunos de ellos como la preocupación por la presencia de beta carbolinas en la maca ${ }^{[23]}$ ya han sido revertidos ${ }^{[22,24]}$.

El AFSSA hace observaciones respecto a la existencia de riesgo, relacionado con el consumo de polvo de maca por parte de sujetos con síndrome metabólico. El informe de AFSSA sobre los estudios realizados ${ }^{[25]}$ en pacientes con síndrome metabólico comparado con el control encontraron un incremento moderado de la presión arterial diastólica y el nivel sérico del aspartato aminotransferasa (AST). El documento indica a su vez que la presión arterial y el nivel sérico del aspartato aminotransferasa al no ser marcadores específicos del síndrome metabólico pueden también afectar a un individuo sano que consume polvo de raíces de maca. El estudio, sin embargo, no demuestra que la tasa de hipertensión se haya incrementado con la administración de maca.

Se indica que en la actualidad no existe información alguna que permita responder a esta observación con relación a la población en general. En ese sentido resulta importante realizar un estudio poblacional en zonas donde el consumo de maca es endémico, lo cual ocurre en la meseta del Bombón en los Andes centrales del Perú, lugar donde se produce la maca $[1,21]$.

La agencia alemana destaca la ausencia de investigaciones sistemáticas, relativas a la evaluación para la salud y los efectos no deseados. Asimismo el Instituto Federal Alemán de Evaluación de Riesgos (BFR), indica que no es posible deducir en este momento, cuáles serían las cantidades de maca a ingerir inocuas para la salud. Hay que tener en cuenta que la biodisponibilidad de los compuestos nutritivos de la maca podrían estar afectados por la calidad del régimen consumido y otros factores de estilo de vida del nativo, siendo necesario caracterizar el régimen habitual y estudiar la frecuencia y consumo de la maca. 
A la fecha existen doce artículos publicados sobre el efecto de la maca en humanos. Estos estudios clínicos han tenido una duración máxima de cuatro meses y han sido llevados a cabo en individuos aparentemente sanos [10,26-29], en post-menopausia [30,31], con disfunción sexual [32,33], con osteoartritis [34], con síndrome metabólico [25] o deportistas [35]. De estos estudios sólo el de Valentová, 2008 indica diferencias en la presión arterial diastólica y en la aspartato aminotransferasa sérica (marcador de función hepática). Gonzales [10], en un estudio doble ciego en varones aparentemente normales, donde se compara un grupo que ha recibido maca gelatinizada (1.5-3.0 gramos diarios por 12 semanas) contra otro grupo randomizado que ha recibido placebo encuentra más bien una disminución de la presión arterial diastólica.

Por todo lo anterior se hace necesario desarrollar un estudio poblacional que nos permita evaluar la seguridad alimentaria y nutricional de una población consumidora tradicional de maca. El presente estudio fue desarrollado para responder en una población de los andes centrales donde consumen maca de manera tradicional las siguientes interrogantes:

¿La maca mejora el estado de salud de las personas que la consumen frecuentemente?,

¿El consumo tradicional de maca produce posibles efectos toxicológicos en el organismo?

\section{Materiales y Métodos}

El estudio es transversal analítico que compara a la población de Carhuamayo, Junín (4146 m snm) según el consumo de maca. El estudio fue aprobado por el Comité de Etica de la Universidad Peruana Cayetano Heredia y de la Universidad de Emory (Atlanta, Georgia). El estudio se desarrolla en dos partes, la primera basada en una encuesta sociodemográfica y de salud, y la segunda parte en una submuestra donde a partir de una muestra de sangre se evalúa la función hepática, renal, y hematológica.

La población de Carhuamayo según el Censo Nacional de Población (INEI, 2007) es de 8,386 habitantes, entre hombres y mujeres. La población a estudiar es la constituida entre lo 35 y más años de edad. Según el Censo de población (INEI, 2007) el universo lo conforman 1490 hombres y 1614 mujeres. El tamaño muestral se ha calculado utilizando la técnica de muestreo aleatorio con un límite de confianza del ( $Z$ ) 95\% y un error relativo de $10 \%$. El cálculo del tamaño muestral es como mínimo de 90 varones y 91 mujeres. Para la submuestras para evaluaciones en sangre se considera un error relativo de $15 \%$. En este caso el tamaño muestral es de 42 para varones y 42 para mujeres.

La muestra final estuvo conformado por 557 entrevistados (150 varones y 407 mujeres) y una submuestras de 193 sujetos a quienes se les tomó una muestra de sangre en ayunas (49 varones y 144 mujeres). Los sujetos fueron clasificados por grupos etáreos y comparados su distribución con el del censo poblacional [36]. La distribución fue similar para la población del censo como para la muestra de estudio $(p>0.05)$. Se han analizado también otras variables como tipo de material en las paredes y material usado para cocinar y estos parámetros en la muestra de estudio tienen una distribución similar a la observada en el censo poblacional $(\phi>0.05)$.

\section{Criterios de Inclusion}

Sujetos residentes en la zona por más de 10 años

Sujetos de ambos géneros mayores o igual a 35 años.

\section{Criterios de Exclusion}

Sujetos no residentes de la zona o residentes menos de 10 años

Edades menores de 35 años

\section{Reclutamiento de los Sujetos de Estudios}

El distrito de Carhuamayo fue dividido en 7 sectores. Se determinó el marco muestral: Contenido de todas las manzanas del distrito. De forma aleatoria se seleccionaron las manzanas $\mathrm{y}$, las viviendas (unidades muestrales) de forma sistemática $(k, k+3, \ldots)$. Si en la vivienda seleccionada no se pudo realizar la entrevista por estar deshabitada o no hay ningún adulto presente, se continúa con la siguiente vivienda seleccionada. En lo posible se evaluó en una casa al padre, a la madre y a un hijo varón o mujer mayor o igual de 35 años. Los sujetos seleccionados participaron voluntariamente en la investigación y firmaron un consentimiento informado. De cada 3 sujetos se seleccionó a uno para la toma de muestra de sangre. El sujeto designado para la toma de muestra de sangre fue citado para que acuda al día siguiente al centro de Salud de la localidad en ayunas. 
Tabla 1. Población del Distrito de Carhuamayo, Junín censada en el 2007 y el tamaño de la muestra estudiada en la misma zona

\begin{tabular}{ccccccc}
\hline $\begin{array}{c}\text { Edad } \\
\text { (años) }\end{array}$ & $\begin{array}{c}\text { Censo } \\
2007\end{array}$ & Muestra & $\begin{array}{c}\text { Censo } \\
2007 \\
\text { Varones }\end{array}$ & $\begin{array}{c}\text { Muestra } \\
\text { Varones }\end{array}$ & $\begin{array}{c}\text { Censo } \\
2007 \\
\text { Mujeres }\end{array}$ & Muestra \\
\hline $35-39$ & $548(17.6)$ & $120(21.5)$ & $232(16.1)$ & $18(12.0)$ & $316(19.0)$ & $102(25.1)$ \\
$40-44$ & $545(17.6)$ & $110(19.7)$ & $239(16.6)$ & $25(16.6)$ & $306(18.4)$ & $85(20.8)$ \\
$45-49$ & $461(14.8)$ & $86(15.4)$ & $242(16.8)$ & $27(18.0)$ & $219(13.2)$ & $59(14.5)$ \\
$50-54$ & $348(11.2)$ & $68(12.2)$ & $165(11.5)$ & $18(12.0)$ & $183(11.0)$ & $50(12.3)$ \\
$55-59$ & $256(8.2)$ & $48(8.6)$ & $133(9.2)$ & $14(9.3)$ & $123(7.4)$ & $34(8.3)$ \\
$60-64$ & $239(7.7)$ & $48(8.6)$ & $113(7.8)$ & $23(15.3)$ & $126(7.6)$ & $25(6.1)$ \\
$65-75$ & $707(22.7)$ & $77(13.8)$ & $316(21.9)$ & $25(17.7)$ & $391(23-5)$ & $52(12.8)$ \\
\hline Total & 3104 & 557 & 1440 & 150 & 1664 & 407 \\
\hline
\end{tabular}

\section{Instrumento}

Se aplicó a cada voluntario un cuestionario con preguntas prefijadas que ya han sido validadas. El cuestionario abarcó los siguientes aspectos:

Características socio demográficas.

Cuestionario de consumo de maca.

Cuestionario sobre fracturas.

Cuestionario de Salud: SF- 36 versión 1.4 con modificaciones [37].

Cuestionario de puntaje de mal de montaña crónico [38]

\section{Procedimiento para la obtención de información}

Todos los participantes han sido evaluados a través de un cuestionario que incluye datos de lugar de nacimiento, tiempo de residencia en la zona, edad, educación, ocupación, talla, peso, hábito de fumar y de beber alcohol, historia médica familiar, tipo de vivienda, tipo de combustible para la cocina.

\section{Consumo de Maca}

Se ha evaluado el tiempo, la frecuencia y la forma de consumo de maca, y la variedad de maca que consume. Se ha tomado información de la cantidad de maca que se consume por vez. Igualmente se ha obtenido información si existe uso de maca durante el embarazo y en la niñez.

\section{Cuestionario de salud, y de fracturas}

El cuestionario de salud e incidencia de fracturas, se realizó a través del cuestionario correspondiente con preguntas estructuradas que tiene como objetivo conocer el estado de salud general de los sujetos y asimismo establecer si existe incidencia de fracturas en la población muestral[39].

El cuestionario de Salud SF-36 (SF-36 Health Survey) es una encuesta de salud diseñada por el Health Institute, New England Medical Center, de Boston Massachusetts, que a partir de 36 preguntas pretende medir ocho conceptos genéricos sobre la salud, esto es, conceptos que no son específicos de una patología, grupo de tratamiento o edad, detectando tanto estados positivos como negativos de la salud física y estado emocional.

El cuestionario de Salud SF-36 ha sido validado en el idioma español [37] y consta de las siguientes 8 dimensiones: función física (10), función social (2), rol físico (4), rol emocional (3), salud mental (5), vitalidad (4), dolor corporal (2) y salud general (6) duración 10 minutos. Alonso y col han validado la versión castellana del SF-36, con un valor de alfa de Cronbach superior a 0,7 (considerado como bueno) en todas los dominios (rango de 0,71 a 0,94), excepto en la relación social (alfa 
$=0,45)$; por tanto, es recomendable para valoraciones de Calidad de vida en pacientes de nuestro entorno.

Los ocho conceptos de salud (dimensiones) determinados en este cuestionario se resumen en la siguiente tabla:

Función física: Grado en el que la falta de salud limita las actividades físicas de la vida diaria, como el cuidado personal, caminar, subir escaleras, coger o transportar cargas, y realizar esfuerzos moderados e intensos.

Rol físico: Grado en el que la falta de salud interfiere en el trabajo y otras actividades diarias, produciendo como consecuencia un rendimiento menor del deseado, o limitando el tipo de actividades que se puede realizar o la dificultad de las mismas.

Dolor corporal: Medida de la intensidad del dolor padecido y su efecto en el trabajo habitual y en las actividades del hogar.

Salud general: Valoración personal del estado de salud, que incluye la situación actual y las perspectivas futuras y la resistencia a enfermar.

Vitalidad: Sentimiento de energía y vitalidad, frente al de cansancio y desánimo.
Función social: Grado en el que los problemas físicos o emocionales derivados de la falta de salud interfieren en la vida social habitual.

Rol emocional: Grado en el que los problemas emocionales afectan al trabajo y otras actividades diarias, considerando la reducción del tiempo dedicado, disminución del rendimiento y del esmero en el trabajo.

Salud mental: Valoración de la salud mental general, considerando la depresión, ansiedad, autocontrol, y bienestar general.

Para el presente estudio se ha reducido del cuestionario original que tiene 36 preguntas a uno recortado con 20 preguntas, donde no se ha considerado la función social por lo tanto incluye sólo 7 dimensiones. Esta prueba recortada supera el estándar propuesto de fiabilidad ( $a$ de Cronbach) de 0.7 [40]. Para validar esta prueba se hizo un estudio piloto en la ciudad de Lima (150 metros sobre nivel del mar) en 83 sujetos (24 varones y 59 mujeres) de edades entre 18 y 93 años. El coeficiente alfa de Cronbach fue de 0.70 . Se encontró una asociación entre edad y puntaje de salud (Figura 1). En la muestra obtenida en Carhuamayo el test de confiabilidad da un valor alfa de Cronbach de $=0.89$, lo que indica la ata confiabilidad de la prueba.

Figura 1. Asociación entre edad y puntaje de estado de salud (Cuestionario SF-36 recortado). Coeficiente de Pearson $(r)=$ $0.45 ; p<0.001$.

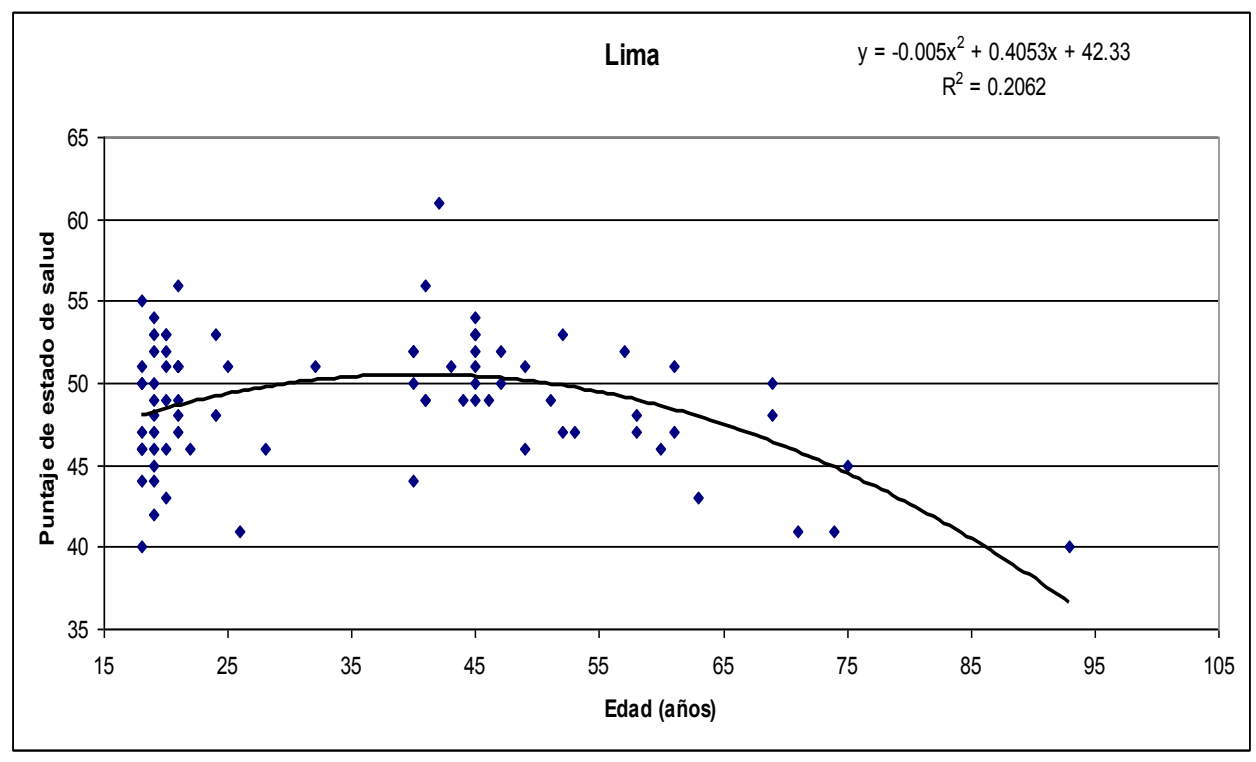

El cuestionario de Incidencia de fracturas consta de 19 preguntas, con una duración de 5 minutos en su ejecución. El cuestionario incluye la siguiente información [39,41]: edad, peso actual $(<60$ ó $\geq 60 \mathrm{Kg})$, facilidad de levantarse de una silla, antecedente de fractura y edad en que ocurrió. En las mujeres se tomó información sobre edad de menarquia, edad de menopausia, lactancia en los dos últimos años, uso de corticoides, calcio, historia materna de fractura de cadera, 
número de caídas en el presente año, disminución de la estatura y encorvamiento de la columna vertebral.

Debido a que la población radica en la altura se ha incluido un cuestionario de puntajes de mal de montaña crónico (MMC). El puntaje de MMC es una medida estandarizada basada en los 7 síntomas y signos más comunes en el MMC [38]. Los puntajes en cada signo o síntoma oscila de 0 (ausencia del signo o síntoma) a 3 (mayor severidad). La suma de los scores va de 0 a 21 . En caso en que se tiene la muestra de hemoglobina cuando esta en varones es mayor o igual de $21 \mathrm{~g} / \mathrm{dl}$; o en mujeres mayor o igual de $18.5 \mathrm{~g} / \mathrm{dl}$ se adiciona 3 puntos al score y se obtiene el puntaje final de MMC. En reciente estudio en varones en cerro de Pasco, Perú $(4340 \mathrm{~m})$ se ha obtenido una mediana de puntaje de MMC (ítems 1-7) de 6 con valores de 4 y 9 para los percentiles 25 y 75 , respectivamente; y de 8 (5/10, percentiles $25 / 75$ ) cuando se incluye la medición de hemoglobina ${ }^{[42] .}$

\section{Variables}

Estado de Salud: Se ha definido a través de un conjunto de preguntas relacionadas al estado general del individuo. Esta variable se ha construido con el cuestionario SF-36 recortado cuyas respuestas utilizan la escala de Lickert. Cada pregunta tiene un valor de que oscilan de 1-2; 1-3 y 1-4. El puntaje total se calcula sumando cada una de las respuestas en cada item. El valor mínimo es de 20 y el máximo de 61.

Se ha evaluado también el cuestionario de salud en función de sus dimensiones. Para ello se da una puntuación que va de 0 a 100 , que consiste en transformar el puntaje a escala de 0 a 100 (lo mejor es 100 y lo peor 0 ). Por ejemplo pregunta de 2 categoría tendrán como puntuación 0 ó 100; de 3 categorías 0 - 50100; con 4 categoría 0-33.3-66.6-100. Luego, los puntajes de items de una misma dimensión se promedian para crear los puntajes de las 7 escalas que van de 0 a 100. En los cuestionarios tomados en Carhuamayo todos los items fueron respondidos.

Consumo de maca es definida como la ingesta de este hipocótilo en el tiempo, forma de presentación (hipocótilo fresco, hipocótilo seco, harina de maca, harina gelatinizada, extractos, pildoras), diferente preparación (sólida y liquida) y variedad de maca (morada, negra, amarilla, roja, mezcla de maca). Será medida como variable ordinal. Se ha determinado el promedio diario de consumo de maca y la variedad de maca más utilizada por los pobladores de Carhuamayo.
Fracturas se define como el número de fracturas que ha tenido por encima de los 40 años de edad. La tasa de fracturas se calcula como el número de fracturas ocurrido después de los 40 años sobre el número total de sujetos mayor de 40 años evaluados. También se ha evaluado la tasa de fracturas en la población general entrevistada.

\section{Evaluaciones Sanguineas}

A los sujetos seleccionados se les tomó en el Centro de Salud de Carhuamayo una muestra de sangre venosa en ayunas entre 8 y $11 \mathrm{am}$. Se han medido marcadores sanguíneos de función hepática, renal, hemoglobina, glicemia y perfil lipídico.

\section{Hemoglobina}

La hemoglobina se midió utilizando un equipo Hemocue y la medición con cintas reactivas. Esta prueba ha sido usada satisfactoriamente en poblaciones de alturas mayores de $4000 \mathrm{~m}$. Asimismo en nuestro laboratorio se ha encontrado un coeficiente de correlación de 0.99 , entre la medición de hemoglobina por Hemocue, y la medición del hematocrito por el método del microhematocrito en una población de varones de Cerro de Pasco (4340 metros de altitud).

\section{Glicemia}

La glicemia se midió por punción capilar en el pulpejo del dedo. Se utilizó un glucómetro marca Accutrend Plus (Mannheim, Germany). El rango normal oscila entre $70-110 \mathrm{mg} / \mathrm{dl}$.

\section{Colesterolemia}

Los niveles de colesterol total, LDL colesterol y HDL colesterol por espectrofotometría. Los rangos normales para colesterol total: < $200 \mathrm{mg} / \mathrm{dl}$. La hipercolesterolemia generalmente definido come $>240$ $\mathrm{mg} / \mathrm{dl}$. Los rangos normales para HDL- colesterol: hombres: 35-55 mg/dl; mujeres: 45-65 mg/dl. Los rangos normales para LDL- colesterol: < $130 \mathrm{mg} / \mathrm{dl}$. VLDL: 5-40 mg/dl.

\section{Trigliceridos}

Se considera como rango normal: $30-150 \mathrm{mg} / \mathrm{dl}$. La hipertrigliceridemia se define como el aumento de los triglicéridos séricos por encima de los $150 \mathrm{mg} / \mathrm{dl}$. 


\section{Presion Arterial}

La medición de la presión arterial, tanto sistólica como diastólica, se realizó con un esfigmomanómetro aneroide. La medición se realizó en la posición sentada y en el brazo izquierdo. Los valores normales son de presión sistólica $<140 \mathrm{~mm} \mathrm{Hg}$ y de presión diastólica $<90$ $\mathrm{mm} \mathrm{Hg}$.

\section{Funcion Hepatica}

Para evaluar daño hepático se midieron los niveles séricos de Alanina aminotransferasa (transaminasa glutámico pirúvica): valores normales $<40 \mathrm{UI} / \mathrm{L}$; y de aspartato amino transferasa (transaminasa glutámico oxalacético): el rango normal es de 10 a 34 UI/L. Para evaluar obstrucción biliar, tanto en el hígado como en los canales mayores de la bilis fuera del hígado se evaluaron los niveles de Gamma-glutamil transpeptidasa: El rango normal es de 0 a $51 \mathrm{UI} / \mathrm{L}$; y de fosfatasa alcalina: El rango normal es de 44 a 147 UI/L (Unidades internacionales por litro). Se considera que hay disfunción hepática cuando ambos (GGT y fosfatasa alcalina) se encuentran aumentados. Para evaluar problemas hepáticos o de vesícula biliar se midió los niveles de bilirrubina total: rango normal: 0.3 a 1.9 $\mathrm{mg} / \mathrm{dL}$. La albúmina sérica es sintetizada por el hígado y es la proteína en el suero más abundante. Se han determinado los niveles de albúmina sérica cuyo valores normales oscilan de 3.4 a 5.4 gramos por decilitro (g/dL).

\section{Funcion Renal}

Se ha evaluado a través de la medición de creatinina en sangre. Cuando los riñones no funcionan bien se acumula la creatinina en sangre. Valores normales: 0.6 a $1.2 \mathrm{mg} / \mathrm{dL}$. Acido úrico en suero: $\mathrm{El}$ ácido úrico se produce del metabolismo de las purinas. Proviene de la alimentación, de la fabricación del propio organismo, en las células y cuando se incrementa la ingesta de purinas en la dieta (carnes, vísceras, mariscos, frutos secos, embutidos). Se considera hiperuricemia cuando su valores exceden $7 \mathrm{mg} / 100 \mathrm{ml}$.

\section{Estadística}

Los datos se ingresaron a una base Excel. Se han realizado técnicas estadísticas descriptivas como medias, medianas, desviación estándar de las variables de respuestas continua. Previo análisis de Kolmogorov Smirnov se aplicó ANOVA o medidas no paramétricas según la distribución fuera paramétrica o no paramétrica respectivamente. Para las variables categóricas se ha utilizado la Prueba de Chi cuadrado.
Para estudiar si el consumo de maca afecta significativamente los niveles de presión arterial sistólica y diastólica, alanino amino transferasa (ALT), aspartato amino transferasa (AST), gammaglutamiltranspeptidasa (GGT), la fosfatasa alcalina, la bilirrubina, la creatinina y el ácido úrico, se realizó análisis según percentiles tiempo de consumo de maca en años, veces de consumo de maca al año y cantidad de hiocótilos de maca consumidos por vez. Se considera un nivel de significancia: $p<0.05$.

\section{Resultados}

El 80.4\% de los entrevistados consumen maca. Los entrevistados que consumen manifestaron que en el $87.9 \%$ de casos, toda la familia consume maca. De los varones estudiados, el $84.7 \%$ consume maca en tanto que en el caso de las mujeres, el 78.9\% consume maca.

\section{Ultima vez que consumió maca}

El 29.36\% de entrevistados refiere haber consumido maca por última vez en los últimos 3 días; el $30.16 \%$ la semana anterior; y el $40.47 \%$ en el mes pasado.

\section{Consumo de maca durante el embarazo.}

El $51.1 \%$ de las mujeres entrevistadas reportan el consumo de maca durante el embarazo. El 78.3\% de las mujeres que consumen maca durante el embarazo lo hacen durante los nueve meses de la gestación; 13\% durante 8 meses; $5.8 \%$ durante 7 meses y $2.9 \%$ durante seis meses. El 65.7\% consume maca durante la gestación 1-3 veces por mes; $18.6 \%$ consume maca 1 vez a la semana; $12.8 \%$, 2-3 veces por semana y $2.8 \%$ de $4-6$ veces por semana.

\section{Consumo de maca en la niñez}

Los entrevistados refieren que el $80.9 \%$ de casos los niños consumen maca. El mayor porcentaje (87\%) inicia el consumo de 1-4 años; el $9.2 \%$ de 5-9 años; el $2.7 \%$ por encima de los 9 años; y $0.92 \%$ en menos de un año de edad.

\section{Razones del consumo de maca}

Casi las tres cuartas partes de los consumidores de maca en Carhuamayo refieren que lo hacen por motivos nutricionales. Tan solo un 4\% lo usa sólo por motivos medicinales. Un $13.8 \%$ de los entrevistados utilizan maca por ambos motivos nutricionales y medicinales (Tabla 2). Los varones como las mujeres muestran un patrón similar de distribución ( $p>0.05)$. 


\section{Variedad de maca que consumen los pobladores de Carhuamayo}

Los pobladores de Carhuamayo entrevistados y que consumen maca refieren en un mayor porcentaje
$(79.9 \%)$ que usan una mezcla de hipocótilos sin identificar la variedad. Un $14.5 \%$ usa la maca amarilla y en menor porcentaje la maca negra, morada y roja (Tabla 3). Los varones como las mujeres muestran un patrón similar de distribución $(p>0.05)$.

Tabla 2. Razones que tienen los pobladores de Carhuamayo $(4100 \mathrm{~m})$, Perú para consumir maca

\begin{tabular}{lcrr}
\hline Razones de consumo de maca & Total & \multicolumn{1}{c}{ Varones } & \multicolumn{1}{c}{ Mujeres } \\
\hline Nutritivo & $324(72.3 \%)$ & $94(74.0 \%)$ & $230(71.7 \%)$ \\
Medicinal & $18(4.0 \%)$ & $5(3.9 \%)$ & $13(4.0 \%)$ \\
Nutritivo+Medicinal & $62(13.8 \%)$ & $14(11.0 \%)$ & $48(14.9 \%)$ \\
Otra razón & $26(5.8 \%)$ & $11(8.7 \%)$ & $15(4.7 \%)$ \\
Nutritivo+otra razón & $17(3.8 \%)$ & $3(2.4 \%)$ & $14(4.4 \%)$ \\
No menciona & $1(0.2 \%)$ & 0 & $1(0.3 \%)$ \\
\hline Total & 448 & 127 & 321 \\
\hline
\end{tabular}

Tabla 3. Variedad de maca (color de hipocótilos) que consumen los pobladores entrevistados de Carhuamayo (4100 m), Perú en los andes centrales

\begin{tabular}{lccc}
\hline \multicolumn{1}{c}{ Variedad de maca } & Total & Varones & Mujeres \\
\hline Mezcla sin identificar variedad & $358(79.9 \%)$ & $102(80.3 \%)$ & $256(79.8 \%)$ \\
Amarilla & $65(14.5 \%)$ & $20(15.7 \%)$ & $45(14.0 \%)$ \\
Negra & $7(1.6 \%)$ & $1(0.8 \%)$ & $6(1.9 \%)$ \\
Morada & $6(1.3 \%)$ & $2(1.6 \%)$ & $4(1.2 \%)$ \\
Roja & $3(0.7 \%)$ & $1(0.8 \%)$ & $2(0.6 \%)$ \\
Más de una variedad & $8(1.8 \%)$ & $1(0.8 \%)$ & $7(2.1 \%)$ \\
No conoce & $1(0.2 \%)$ & 0 & $1(0.3 \%)$ \\
\hline Total & 448 & 127 & 321 \\
\hline
\end{tabular}

\section{Presentación en que consuman maca los pobladores de Carhuamayo}

Mas de $85 \%$ de la población entrevistada que consume maca utiliza la presentación de hipocótilos secos que luego de ser procesada (cocción con agua) es consumida. La siguiente preparación más utilizada es la harina de maca. Los varones como las mujeres muestran un patrón similar de distribución $(p>0.05)$. El uso de maca fresca es bajo $(<1 \%)$ (Tabla 4$)$.

\section{Formas de consumo de la maca en Carhuamayo}

La forma de consumo más frecuente es la bebida (jugo, licuado). Ya sea como forma única o combinada con otra forma de uso, el $95.3 \%$ de los entrevistados que consumen maca lo utilizan en forma de bebida. El 65.6\% lo usa solo como bebida. La segunda forma más común de uso es como mazamorra. Tanto los varones como las mujeres utilizan estas formas de presentación en la misma proporción que la descrita para la población general $(p>0.05)$ (Tabla 5). 
Tabla 4. Presentación que consumen maca los pobladores entrevistadosa de Carhuamayo, Perú (4100 m)

\begin{tabular}{lccc}
\hline Presentación de la maca & Total & Varones & Mujeres \\
\hline Hipocótilo fresco & $4(0.9 \%)$ & 0 & $4(1.2 \%)$ \\
Hipocótilo seco & $336(75.0 \%)$ & $93(73.2 \%)$ & $243(75.7 \%)$ \\
Harina de maca & $25(5.6 \%)$ & $6(4.7 \%)$ & $19(5.9 \%)$ \\
Harina gelatinizada & $1(0.2 \%)$ & 0 & $1(0.3 \%)$ \\
Extractos de maca & $2(0.4 \%)$ & $1(0.8 \%)$ & $1(0.3 \%)$ \\
Píldora/Tabletas/pastillas & 0 & 0 & \\
& & $6(4.7 \%)$ & $7(2.2 \%)$ \\
Hipocótilo fresco y seco & $13(2.9 \%)$ & $20(15.7 \%)$ & $39(12.1 \%)$ \\
Hipocótilo seco y harina & $59(13.2 \%)$ & $1(0.8 \%)$ & $7(2.2 \%)$ \\
Otra combinación & $8(1.8 \%)$ & 127 & 321 \\
\hline Total & 448 & & \\
\hline
\end{tabular}

Tabla 5. Formas de consumo de maca de los pobladores de Carhuamayo entrevistados

\begin{tabular}{lccc}
\hline \multicolumn{1}{c}{ Forma de consumo } & Total & Varones & Mujeres \\
\hline Bebida & $294(65.6 \%)$ & $85(66.9 \%)$ & $209(65.1 \%)$ \\
Aguardiente & $4(0.9 \%)$ & $1(0.8 \%)$ & $3(0.9 \%)$ \\
Mazamorra & $11(2.4 \%)$ & $4(3.1 \%)$ & $7(2.2 \%)$ \\
Sopa & $2(0.4 \%)$ & 0 & $2(0.6 \%)$ \\
Otra forma & $2(0.4 \%)$ & $2(1.6 \%)$ & 0 \\
Bebida + Mazamorra & $115(25.6 \%)$ & $29(22.8 \%)$ & $86(26.8 \%)$ \\
Bebida + cualquier otra forma & $18(4.0 \%)$ & $5(3.9 \%)$ & $13(4.0 \%)$ \\
Mazamorra + otra forma & $2(0.4 \%)$ & $1(0.8 \%)$ & $1(0.3 \%)$ \\
\hline Total & 448 & 127 & 321 \\
\hline
\end{tabular}

\section{Cantidad de maca consumida}

En la Tabla 6 se presentan los datos de la cantidad de maca consumida cuando lo hacen como bebida. El mayor porcentaje de entrevistados que utilizan maca como bebida consumen $250 \mathrm{ml}(58.5 \%)$, en menor proporción $500 \mathrm{ml}(21.2 \%)$. Los varones y las mujeres siguen la misma distribución de consumo $(p>0.05)$.
Cuando la maca es consumida en plato, el más frecuente es el consumo del contenido de un plato mediano (61.1\% y $57.4 \%$ para el consumo de mazamorra/sopa o cualquier otra forma de preparación en plato, respectivamente). Cuando se expresa en términos de hipocótilos, los entrevistados refieren que en un 47\% consumen al día de 10-20 hipocótilos; 30\% de $<10$ hipocótilos de maca, y 23\% >20 hipocótilos. 
Tabla 6. Cantidad ( $\mathrm{ml}$ ) consumida de maca por vez por los pobladores de Carhuamayo que lo utilizan como bebida

\begin{tabular}{cccc}
\hline & Total & Varones & Mujeres \\
\hline No consume maca como bebida & $14(3.1 \%)$ & $4(3.1 \%)$ & $10(3.1 \%)$ \\
$150 \mathrm{ml}$ & $60(13.3 \%)$ & $17(13.4 \%)$ & $43(13.4 \%)$ \\
$250 \mathrm{ml}$ & $262(58.5 \%)$ & $65(51.2 \%)$ & $197(61.4 \%)$ \\
$500 \mathrm{ml}$ & $95(21.2 \%)$ & $36(28.3 \%)$ & $59(18.4 \%)$ \\
$750 \mathrm{ml}$ & $17(3.8 \%)$ & $5(3.9 \%)$ & $12(3.7 \%)$ \\
\hline Total & 448 & 127 & 321 \\
\hline
\end{tabular}

De acuerdo a un estudio previo en la zona de Carhuamayo se ha demostrado que el peso promedio de la maca de las variedades negra, roja y amarilla es de 13 gramos [4]. En resumen el $47 \%$ de los consumidores de maca reciben de 130-260 gramos diarios, el 30\% consume 65 gramos diarios en promedio y $23 \%>260$ gramos de hipocótilos de maca.

\section{Características sociodemográficas y fisiológicas}

Tanto la edad, tiempo de residencia en la zona, y la proporción de varones y mujeres es similar en el grupo que consume y no consume maca en Carhuamayo ( $p>0.05)$ (datos no mostrados). La presión arterial sistólica fue menor en los que consumen maca $(112.7 \pm 0.59 \mathrm{~mm} \mathrm{Hg}$ vs $115.1 \pm 1.06 \mathrm{~mm} \mathrm{Hg} ; p<0.05)$ al igual que el Indice de Masa Corporal $(26.69 \pm 0.21$ vs $\left.28.12 \pm 0.52 \mathrm{Kg} / \mathrm{m}^{2} ; \quad p<0.05\right)$. No se observaron diferencias en el perímetro abdominal ni en la presión arterial diastólica $(p>0.05)$. En el caso de las mujeres entrevistadas, ni la edad de menarquia ni la edad de menopausia fueron diferentes cuando se les comparaba en función del consumo de maca $(p>0.05)$.

\section{Maca y Salud}

En la Figura 2 se aprecia las curvas de asociación entre edad y puntaje de estado de salud en los pobladores de Carhuamayo que consumen (_) y que no consumen maca (----). En los pobladores que no consumen maca el puntaje de estado de salud disminuye significativamente de manera cuadrática desde los 35 años hasta los 75 años de edad $(r=0.47 ; p<0.01)$. Este patrón es similar al observado en el estudio piloto en la ciudad de Lima a 150 metros de altura (Figura 1). En el caso de los pobladores de Carhuamayo que consumen maca, el puntaje de salud se mantiene constante en el rango de edad estudiado entre 35 y 75 años de edad $(r=0.12 ; p>0.05)$.

Con respecto a las dimensiones de salud conformadas por la aplicación del cuestionario de Salus, los resultados se encuentran expresados en la Tabla 7. Las dimensiones de Salud General, Función Física. Dolor, Vitalidad y el Promedio General fueron significativamente diferentes entre los grupos que consumen y no consumen maca. Puntaje general de salud indica que los que consumen maca presentan mejor estado de salud, basado en el cuestionario, que los que no utilizan maca. 
Figura 2. Asociación entre puntaje de estado de salud y edad en pobladores de Carhuamayo. Línea cerrada: Consumen maca $(t=0.12 ; p>0.05)$. Línea abierta: No Consumen maca $(t=0.47 ; p<0.01)$.

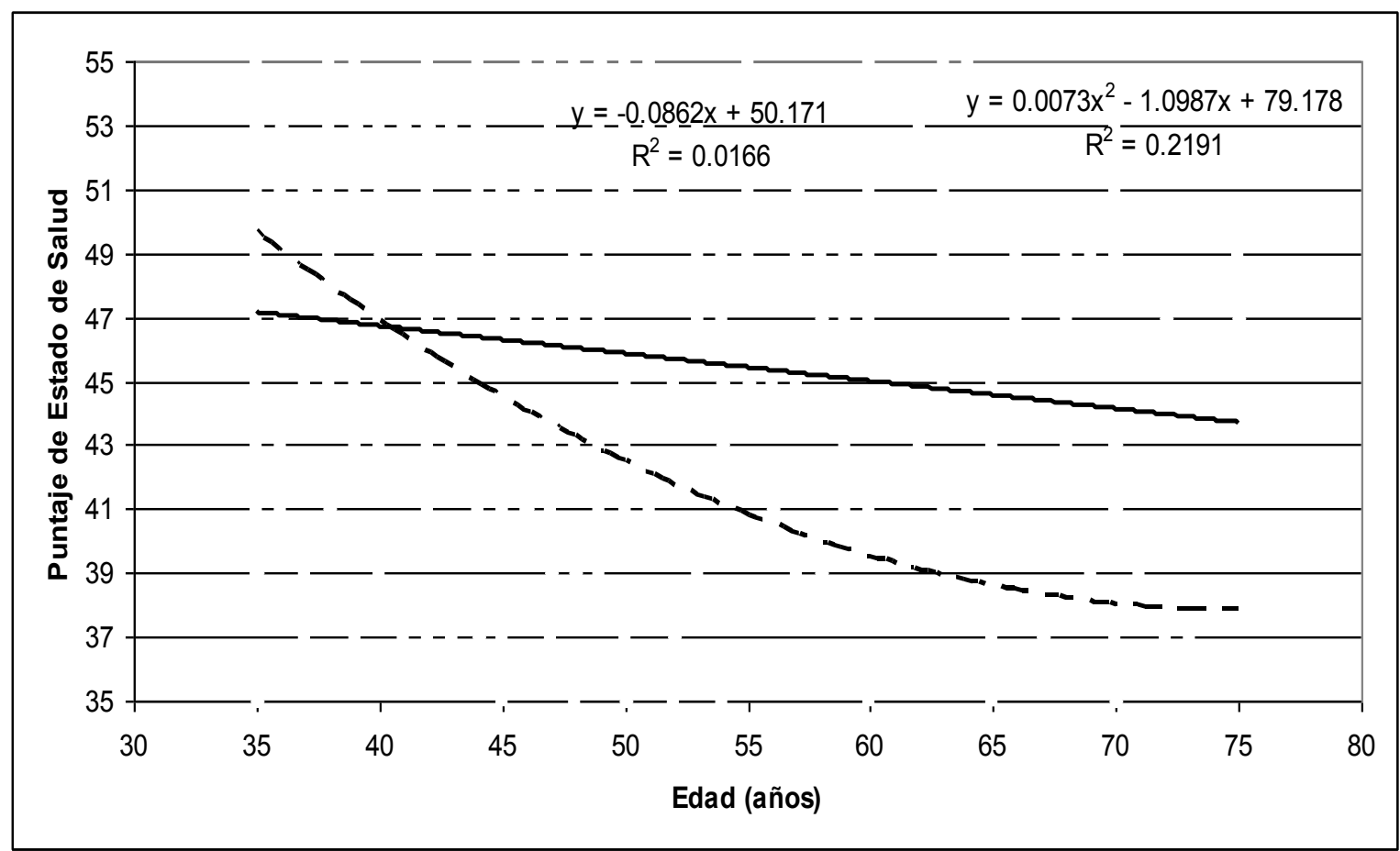

Tabla 7. Puntajes de dimensiones de salud utilizando el cuestionario de salud en pobladores entrevistados en Carhuamayo

\begin{tabular}{lccc}
\hline \multicolumn{1}{c}{ Dimensión de salud } & $\begin{array}{c}\text { No consumen } \\
\text { maca }\end{array}$ & Consumen maca & Significancia \\
\hline Salud General & $49.04 \pm 2.83$ & $55.38 \pm 1.24$ & $<0.05$ \\
Función Física & $66.15 \pm 2.93$ & $77.59 \pm 1.20$ & $<0.01$ \\
Rol físico & $55.96 \pm 4.78$ & $64.96 \pm 2.26$ & $\mathrm{NS}$ \\
Rol emocional & $65.14 \pm 4.59$ & $62.95 \pm 2.28$ & $\mathrm{NS}$ \\
Dolor & $66.51 \pm 3.06$ & $73.77 \pm 1.42$ & $<0.05$ \\
Vitalidad & $50.86 \pm 2.35$ & $57.99 \pm 1.10$ & $<0.01$ \\
Salud mental & $58.77 \pm 1.92$ & $62.48 \pm 0.92$ & $\mathrm{NS}$ \\
Promedio General & $58.92 \pm 2.27$ & $65.02 \pm 1.05$ & $<0.05$ \\
\hline
\end{tabular}


Los datos son medias \pm error standard. Los puntajes de estado de salud han sido transformados a valores que oscilan de 0 a 100.

\section{Maca y Fractura}

El porcentaje de fracturas en pobladores de Carhuamayo mayores de 40 años participantes del estudio fue de $3.3 \%$ en comparación al $8.64 \%$ de la población que no consume maca (Chi cuadrado $=4.20 ; p$ $<0.05$ ) (Figura 3). Igualmente la tasa de fracturas por caídas leves es significativamente mayor en las personas de Carhuamayo que no consumen maca (Chi cuadrado $=4.63 ; p<0.05)$.

Figura 3. Porcentaje de sujetos con fracturas en la población entrevistada en Carhuamayo.

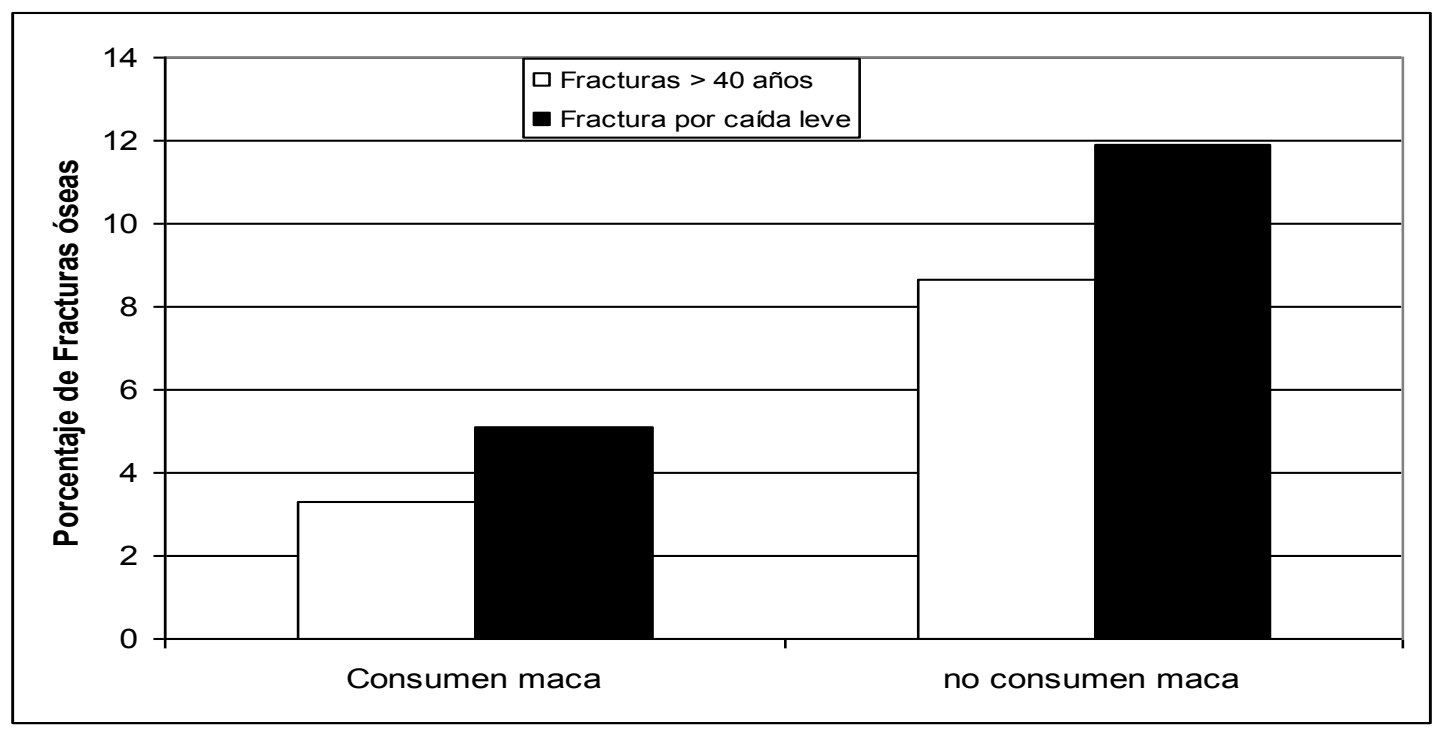

$p<0.05$ para fracturas por caídas leves y fracturas en personas mayores de 40 años. Los que consumen maca presentan una menor tasa de fracturas.

La pregunta de si el entrevistado puede levantarse 5 veces de la silla sin usar los brazos es utilizado en las pruebas de riesgos de fractura. El rendimiento en la prueba sentarse-levantarse de una silla correlaciona con mediciones de fuerza de las extremidades inferiores (fuerza de los extensores de la rodilla), la velocidad al caminar, la capacidad de subir escaleras o el equilibrio. También es efectivo para discriminar entre los mayores que sufren caídas y los que no las sufren y para detectar riesgo de sufrir caídas. Esta pregunta es respondida positivamente en mayor porcentaje $(76 \%)$ por las personas que consumen maca que aquellas que no la consumen (61\%; Chi cuadrado: $10.21 ; p<0.01)$.

\section{Maca y Score de Mal de Montaña Crónico}

En la Tabla 8 se aprecian los resultados de la evaluación del score de mal de montaña crónico basado en signos y síntomas propios de esta patología. La población que consume maca presenta un menor puntaje total de signos y síntomas de mal de montaña crónico en Carhuamayo $(4100 \mathrm{~m})$ que aquellos que no consumen $\operatorname{maca}(p<0.05)$. 
Tabla 8. Puntaje de signos y síntomas de mal de montaña crónico en pobladores de Carhuamayo (4100 m) que consumen o no consumen maca

\begin{tabular}{lccc}
\hline Signo y síntoma de MMC & Consume maca & No consume maca & Significancia \\
\hline Dificultad para respirar o & $0.69 \pm 0.05$ & $1.05 \pm 0.11$ & $<0.01$ \\
palpitaciones al corazón & & & \\
Dificultad para dormir & $0.51 \pm 0.04$ & $0.71 \pm 0.09$ & $<0.05$ \\
Cianosis & $0.35 \pm 0.03$ & $0.32 \pm 0.06$ & $\mathrm{NS}$ \\
Dilatación de venas de & $0.50 \pm 0.03$ & $0.59 \pm 0.07$ & $\mathrm{NS}$ \\
manos/pies & & & $\mathrm{NS}$ \\
Parestesia en extremidades & $0.72 \pm 0.04$ & $0.77 \pm 0.09$ & $<0.01$ \\
Dolor de cabeza & $0.98 \pm 0.04$ & $1.26 \pm 0.10$ & $<0.05$ \\
Tinnitus (zumbido de & $0.48 \pm 0.03$ & $0.65 \pm 0.07$ & \\
oídos) & & & $<0.05$ \\
\hline TOTAL & $4.24 \pm 0.15$ & $5.34 \pm 0.35$ & \\
\hline
\end{tabular}

El análisis de signos y síntomas individuales permite demostrar que los signos y síntomas de MMC que no se observan cuando se consume maca son los de dificultad respiratoria o palpitaciones $(p<0.01)$, dificultad para dormir $(\phi<0.05)$, dolor de cabeza $(p<0.01)$ y tinnitus $(p<0.05)$.

En varones el consumo de maca favorece una menor concentración de hemoglobina a medida que se incrementa la edad siendo la diferencia significativa con respecto a los valores en varones que no consumen maca (Figura 4). En mujeres los niveles de hemoglobina se mantienen en valores estables entre los 35 y 75 años en ambos grupos. La tasa de eritrocitosis excesiva controlado por sexo es de $20.93 \%$ en la población que no consume maca y $10.73 \%$ en la población que consume maca $(p<0.01$, Chi cuadrado=3.85).

Figura 4. Asociación entre hemoglobina ( $\mathrm{g} / \mathrm{dl})$ y edad (años) en varones de Carhuamayo (4100 m) que consumen maca (_) y en aquellos que no consumen maca (---). $Y=-0.01 x+22.63 ; r=0.12 ; p>0.05(---) . Y=0.001 X 2-0.20 x+26.40 ; t=0.32 ; p<0.05(\longrightarrow)$.

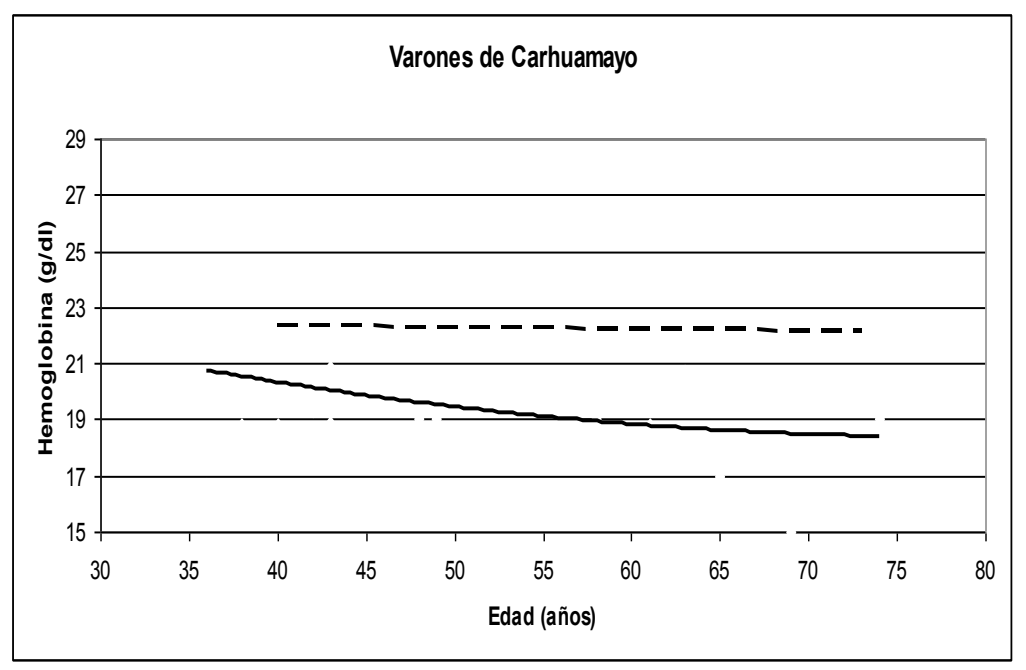


Se aprecia una buena asociación entre los puntajes de MMC y los puntajes de Estado de Salud en los pobladores de Carhuamayo entrevistados $(r=-0.51)$. A mayor puntaje de MMC hay menor puntaje del estado de salud $(\phi<0.001)$.

En las Figuras 5 y 6 se aprecia que el cocinar con biomasa (champa, bosta, leña) se asocia con menores puntajes de estado de salud (Figura $5 ; p<0.01$ ) y mayores de puntajes de signos y síntomas de mal de montaña crónico (Figura $6 ; p<0.01$ ). El uso de maca mejora el puntaje de salud principalmente en los que usan biomasa para cocinar $(p<0.05)$ y disminuye el puntaje de signos y síntomas de mal de montaña crónico. El efecto de disminuir el puntaje de MMC parece ser general pues se observa también en aquellos casos que utilizan gas para cocinar o no cocinan $(p<0.05)$.

Figura 5. Asociación entre el uso de combustible para cocinar y el puntaje de estado de salud en pobladores de Carhuamayo $(4100 \mathrm{~m})$. En el grupo de gas se incluye también a las personas entrevistadas que no cocinan. Los datos son medias \pm ES. $p$ $<0.01$ entre los que usan biomasa para cocinar en comparación a los que usan gas. $p<0.05$ entre los pobladores que usan biomasa.

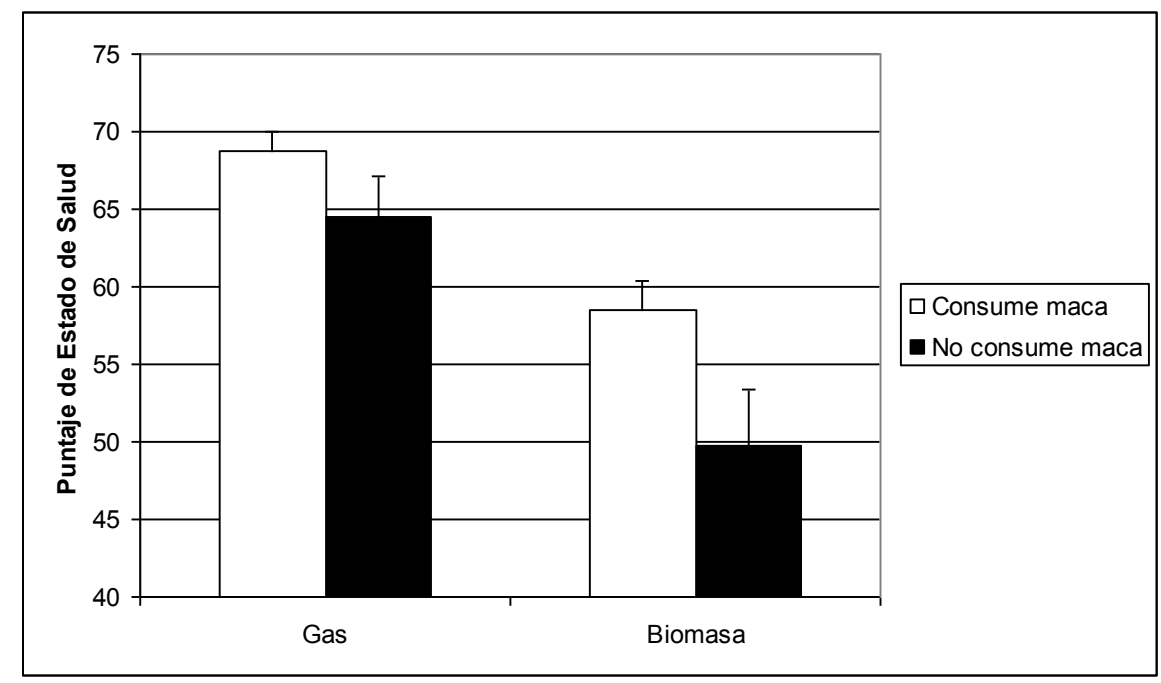

Figura 6. Asociación entre el uso de combustible para cocinar y el puntaje de signos y síntomas de mal de montaña crónico en pobladores de Carhuamayo $(4100 \mathrm{~m})$. En el grupo de gas se incluye también a las personas entrevistadas que no cocinan. Los datos son medias \pm ES. $p<0.01$ entre los que usan biomasa para cocinar en comparación a los que usan gas. $p<0.05$ entre los pobladores que usan biomasa.

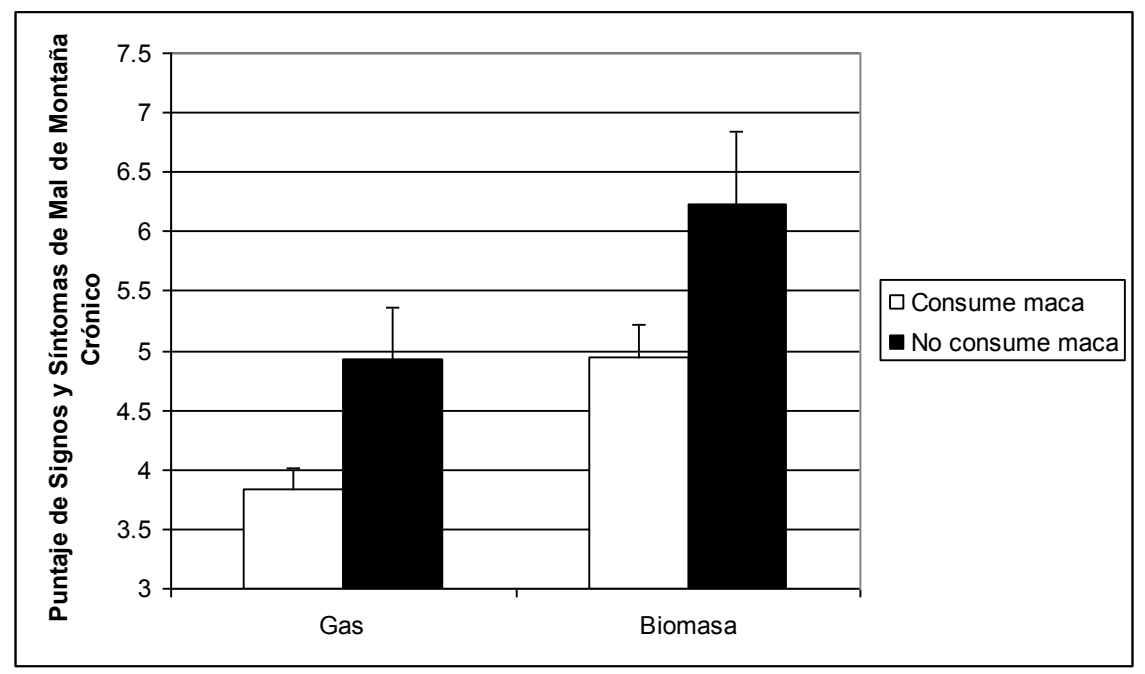




\section{Enfermedad y Consumo de Maca}

De acuerdo al análisis, los que consumen maca presentaron en menor proporción enfermedad en las dos últimas semanas (33\%) comparado a los que no consumen maca, quienes en $44 \%$ de los casos refirieron haberse enfermado en las dos últimas semanas $(p<0.05)$.

\section{Perfil metabólico y lipídico y Maca}

Los niveles de glucosa, lactato y los de colesterol, VLDL, LDL, HDL y triglicéridos fueron similares en los pobladores que consumen y no consumen maca (Tabla 9).

Tabla 9. Mediana y percentiles 10 y 90 de las variables bioquímicas de los pobladores de Carhuamayo (4100 m) en función del consumo tradicional de maca

\begin{tabular}{lrrr}
\hline & No consume maca (43) & Consume maca (151) & $\boldsymbol{p}$ \\
\hline Carbohidratos & & & \\
Glucosa & $95(82 / 120.8)$ & $96(88.8 / 121.2)$ & $>0.05$ \\
Lactato & $3.7(2.8 / 4.3)$ & $4.0(2.9 / 4.9)$ & $>0.05$ \\
Perfil lipídico & & & \\
Triglicéridos & $181.5(100.1 / 321.9)$ & $180.5(81.1 / 332.6)$ & $>0.05$ \\
Colesterol Total & $149.6(119.1 / 195.8)$ & $144.6(100.3 / 202.5)$ & $>0.05$ \\
VLDL & $36.3(20.0 / 64.4)$ & $36.1(16.2 / 66.5)$ & $>0.05$ \\
LDL & $92.3(65.8 / 137.9)$ & $87.3(55.0 / 124.2)$ & $>0.05$ \\
HDL & $31.2(25.0 / 44.9)$ & $35.1(21.2 / 46.7)$ & $>0.05$ \\
Función hepática & & & \\
Aspartato amino AST & $29.0(19.1 / 47.9)$ & $29.0(19.0 / 42.9)$ & $>0.05$ \\
Alanino amino transferasa (ALT) & $18.0(11.1 / 31.6)$ & $18.0(11.0 / 32.9)$ & $>0.05$ \\
Fosfatasa alcalina & $92.5(74.2 / 143.3)$ & $100(62 / 142.6)$ & $>0.05$ \\
Gamma Glutamil Transpeptidasa & $23.5(18.0 / 45.70)$ & $27.5(14.1 / 75.9)$ & $>0.05$ \\
Bilirrubina total & $0.55(0.3 / 1.0)$ & $0.60(0.30 / 1.09)$ & $>0.05$ \\
Colesterol/HDL & $4.7(3.3 / 7.0)$ & $4.2(2.9 / 6.3)$ & $>0.05$ \\
Albúmina & $4.5(3.6 / 6.5)$ & $4.4(2.8 / 5.0)$ & $>0.05$ \\
Función renal & & & \\
Creatinina & $0.70(0.60 / 0.80)$ & $0.70(0.60 / 0.90)$ & $>0.05$ \\
Ácido úrico & $4.6(3.5 / 6.5)$ & $4.8(3.3 / 6.9)$ & $>0.05$ \\
\hline
\end{tabular}

Los valores son medianas. Entre paréntesis se encuentran los percentiles 10 y 90 de cada variable.

\section{Función hepática y Maca}

Los niveles de AST, ALT, fosfatasa alcalina, GGT, bilirrubina total y albúmina son similares en los que consumen y en los que no consumen maca $(p>0.05)$ (Tabla 9).

\section{Función renal y Maca}

Los niveles de creatinina y de ácido úrico fueron similares en los pobladores que consumen y no consumen maca $(p>0.05)$ (Tabla 9).

No se observan tampoco cambios cuando se analizan según percentil de consumo de hipocótilos por vez, tiempo en que se consume maca o número de veces de consumo de maca por año.

\section{Discusion}

La maca es un alimento producido exclusivamente en los Andes centrales del Perú según lo confirman las descripciones iniciales del Cronista español Bernabé Cobo en el Siglo XVII [2] y los posteriores relatos de otros cronistas e investigadores científicos. En el Siglo XX la maca continúa siendo un producto de los Andes centrales; así, en 1964, la maca es descrita como exclusiva de los Andes centrales [43]. En el 2005, en la provincia de Junín, en los Andes centrales, se produjo 15,257 toneladas métricas de maca comparado a 6 TM en el Cuzco ${ }^{[10]}$. Esto es de particular interés puesto que en la década del 90 en el siglo pasado, el Gobierno peruano promovió el cultivo masivo de maca dado el interés de los mercados internacionales; sin embargo, las cosechas no prosperaron, lo que indica la perfecta interacción 
entre el ambiente de los andes centrales y la calidad de la maca.

Cuando la semilla de maca producida en Junín ha sido llevada y sembrada en suelo europeo, el hipocótilo que se produce tampoco tiene la característica del producido en los Andes centrales siendo más bien adelgazado [44]. Esto nos revela que la maca ha requerido un periodo de adaptación y que su morfología y composición es una respuesta a dicho clima agreste y característico de los Andes centrales del Perú.

El estudio realizado en una población tradicionalmente productora y consumidora de maca, como es Carhuamayo, revela que en la actualidad el $80 \%$ de dicha población consume maca. El 85\% de esta población lo usa por motivos nutricionales como ha sido destacado en los escritos de Cobo en 1653. Estudios experimentales han demostrado que efectivamente la maca tiene importantes propiedades nutritivas ${ }^{[4]}$ aumentando con ello su importancia en estas zonas donde por las características geográficas y ambientales dificultan el cultivo de muchas otras plantas para el sustento humano.

Si bien tradicionalmente la maca ha sido reconocida por sus cualidades en la fertilidad [2,6], los cuales han sido en los últimos años verificados científicamente $[1,11,46]$, el presente estudio también ha demostrado que la población de Carhuamayo que consume maca tiene mejores puntajes de estado de salud, menores puntajes de signos y síntomas de mal de montaña crónico, y menores tasas de fractura luego de 40 años que los pobladores de Carhuamayo que no consumen maca.

Es de particular interés la demostración que el puntaje de estado de salud que normalmente disminuye con la edad, como se observa de 35 a 70 años en los pobladores de Carhuamayo que no consumen maca, no se observa lo mismo en aquellos que consumen maca donde más bien el puntaje de salud a los 35 años es más alto que en aquellos que no consumen maca y se mantiene constante hasta los 75 años. Entre las dimensiones de salud que mide el cuestionario utilizado [37] destacan que la maca presenta mejores puntajes en las dimensiones de salud general, función física, dolor, y vitalidad más no en rol físico y emocional ni en salud mental. Los pobladores de las zonas altoandinas en muchos casos dedicados a la agricultura o al comercio como medio de subsistencia se dedica a su trabajo independiente de si se siente física o emocionalmente mal y por ello estas dimensiones no se afectan con el consumo de maca.
El caso de falta de significancia estadística cuando se evalúa la dimensión de salud mental llama la atención pues en diferentes estudios se ha demostrado el efecto favorable de la administración de maca en el stress, en los puntajes de ansiedad y depresión, y en aprendizaje $y$ memoria en humanos $y$ animales de laboratorio ${ }^{[10,17,30,47]}$.

La menor tasa de fracturas en la población que consume maca se asocia a la demostración experimental que en ratas ovariectomizadas se revierte la osteoporosis cuando se administra maca [48,49]. La mayor capacidad para levantarse de una silla por cinco veces seguida en las personas en Carhuamayo que consumen maca indica una mayor fuerza muscular que a su vez es protector para el riesgo de fracturas.

Las poblaciones en las grandes alturas se caracterizan por tener una enfermedad singular que es el mal de montaña crónico (MMC) [42]. Esta patología se asocia a eritrocitosis excesiva que en varones se presentan con hemoglobina mayor o igual a $21 \mathrm{~g} / \mathrm{dl}$ y en mujeres con hemoglobina mayor o igual a $18.5 \mathrm{~g} / \mathrm{dl}$ [38]. La maca se asocia a disminución de la $\mathrm{Hb}$ en varones y a menores puntajes de signos y síntomas de mal de montaña crónico. Nuestro trabajo también ha permitido demostrar que las personas que tienen puntaje elevado de signos y síntomas de MMC también presentan puntajes bajos en el Estado de Salud. En el presente estudio hemos observado que con la menopausia el puntaje de MMC aumenta, lo que indicaría que el estradiol sería protector de la eritrocitosis excesiva, y que la testosterona sería más bien factor de riesgo de MMC como ha sido demostrado recientemente [50]. Si bien es cierto la maca no afecta los niveles hormonales [28,30], ni afecta el receptor de andrógenos ${ }^{[51]}$ es probable que actúe como un modulador selectivo del receptor de estrógenos o en pasos posteriores a la activación de los receptores de hormonas sexuales.

Lo más importante del estudio es que se ha demostrado que el consumo tradicional se basa en el uso de hipocótilos secos de maca, el proceso de hervido previo a su consumo, el ser ingerido mayormente como jugos o licuados y en cantidades mayores a 20 gramos/día. Estos valores son superiores a lo que se consumen nacional o internacionalmente utilizando productos comerciales. Igualmente se demuestra que el consumo de maca es considerado seguro luego de las evaluaciones de presión arterial, índice de masa corporal, parámetros de función hepática, renal, de perfil de carbohidratos y de perfil lipídico. 
En los parámetros de función hepática se han evaluado la funcionalidad de los hepatocitos (AST, ALT, albúmina) y los canalículos biliares (Gamma glutamil transpeptidasa, fosfatasa alcalina, bilirrubina) [52]. Ninguna de estas variables fue afectada por el consumo de maca. Valentova y col [25] en un grupo de pacientes con sindrome metabólico encontró que el tratamiento durante 90 días con maca resultó en un leve pero significativo aumento de los niveles de AST en tanto que los niveles de ALT y de albúmina no fueron afectados. Nuestros resultados donde se evalúan los niveles de AST, ALT, GGT, fosfatasa alcalina y bilirrubina total no muestran ninguna diferencia entre los que consumen maca o no; ni en función de la cantidad ni tiempo de consumo. Los niveles de ALT son los más específicos para la función hepática puesto que los niveles de AST se asocian a las funciones de hígado, corazón, músculo, riñón, cerebro y glóbulos rojos [52]. En otro estudio donde un grupo de deportistas recibió por 60 días 1.5 gramos de maca fresca en forma de cápsulas no se observó diferencias en los niveles de ALT ni de AST [29]. En un estudio experimental realizado en ratones en nuestro laboratorio, el tratamiento por 8 meses con maca roja, maca amarilla y maca morada no mostró elevación en los niveles de AST ni de ALT (Yucra y Gonzales, no publicado).

La función renal tampoco muestra alteración por efecto del consumo de maca. Esto coincide con los resultados obtenidos en deportistas por Ronceros y col [29] donde evalúan los niveles de creatinina en suero. Nuestro estudio adicionalmente mide también los niveles de ácido úrico que no difieren entre los que consumen y no consumen maca. Valentova y col [25] en sujetos con sindrome metabólico no encuentran alteraciones en los niveles de creatinina, ácido úrico y de urea, otro marcador de la función renal, entre aquellos tratados con maca y los no tratados.

El perfil lipídico y de carbohidratos fueron similares entre los grupos que consumen y no consumen maca. Esto es similar a lo observado por Valentova y col[25] en un grupo de sujetos con síndrome metabólico.

Nuestros resultados no muestran un efecto deletéreo del consumo de la maca sobre la presión arterial, más bien se observa un menor valor de la presión arterial sistólica en las personas que consumen maca. Valentova por el contrario encontró que la presión arterial diastólica se incrementó en un grupo particularmente en mujeres con sindrome metabólico tratadas con $0.6 \mathrm{~g} /$ día de maca por 3 meses [25]. Previamente Gonzales y col (2006) [27] no mostraron aumento de la presión arterial en varones tratados por 3 meses con maca entre 1.5-3.0 gramos/ día [10]. Más bien se observó una disminución de la presión arterial tanto sistólica como diastólica [10]. Esta disminución en la presión arterial podría deberse al alto contenido de potasio en los hipocótilos de maca ${ }^{[1]}$.

La maca se caracteriza por su alto contenido en glucosinolatos [53.54], una familia de compuestos que existen en todas las brasicaceas (como la maca) y que se utiliza en la dieta por la creencia de que su consumo disminuye la presencia de cáncer [55,56].

En resumen los resultados del presente estudio demuestran que la maca tiene un perfil de bioseguridad dentro de un rango apreciable en cantidad y en tiempo de uso, particularmente el consumo de maca luego que esta ha sido deshidratada naturalmente como tradicionalmente se describe [2,7]. Este alimento nativo de los Andes centrales del Perú desde periodos pre-incaicos y que estuvo en peligro de extinción [9], se constituye en la actualidad en una importante fuente de subsistencia para las zonas alto-andinas y de interés por sus propiedades nutritivas y medicinales en muchas partes del mundo.

\section{Agradeciemientos}

Este estudio ha sido apoyado económicamente por un Grant del Programa Fogarty de los Institutos Nacionales de Salud de los Estados Unidos $(\mathrm{NIH}$ Research Grant \# 5-D43TW005746-04 funded by the Fogarty International Center, National Institutes on Environmental Health Services, National Institute for Occupational Safety and Health, and the Agency for Toxic Substances and Disease Registry).

Agradezco a todos los miembros del Laboratorio de Endocrinología y Reproducción que han participado en el trabajo de campo y en la elaboración de la base de datos.

\section{Referencias Bibliográficas}

1. Valerio L, Gonzales GF. Toxicological Aspects of South American Herbs: Uncaria tomentosa (Cat's Claw) and Lepidium meyenii (Maca). A Critical Synopsis. Toxicological Reviews 2005; 24: 11-35.

2. Cobo B. Historia del Nuevo Mundo. Biblioteca de Autores Españoles. 1653. Sevilla:España. 1956. 430 pp.

3. Cieza de León P. Crónicas del Perú. Primera Parte 1553. 240:354.

4. Gonzales GF. Maca: From the Tradition to the Sciences. Lima,Peru. UPCH:Lima. 2006a:250 pp 
5. Vásquez de Espinoza A. Compendio y Descripción de las Indias Occidentales. Biblioteca de Autores Españoles:Madrid, España. 1969: 330-332; 355.

6. Ruiz H. Relación histórica del viaje a los reinos del Perú y Chile, 1777-1788, Madrid. Academia de Ciencias Exactas: Fis y Nat 1952: 526 pp.

7. De Rivero y Ustariz ME. Memoria sobre algunos ramos de la agricultura del Perú. En: Colección de Memorias Científicas, Agrícolas e Industriales. Tomo II. Imprenta de H. Goemare: Bruselas. 1897: 218-228.

8. Chacón G. Estudios fitoquímicos de Lepidium meyenii Walp. Tesis de Bachiller en Biología. Universidad Nacional Mayor de San Marcos. Lima:Perú. 1961.

9. National Research Council. Lost crops of the Incas: Little-known plants of the Andes with promise for Worldwide cultivation. Washington DC: The National academies Press. 1989: 56-65.

10. Gonzales GF: Biological effects of Lepidium meyenii, Maca, a plant from the highlands of Peru. In. Natural Products. Series: Recent Progress in Medicinal Plants. Ed. V.K. Singh, R. Bhardwaj, JN. Govil, RKr. Sharma. Studium Press LLC: USA. 2006;15: 217-242.

11. Gonzales C, Rubio J, Gasco M, Nieto J, Yucra S, Gonzales GF: Effect of short term and long term treatments with three ecotypes of Lepidium meyenii (MACA) on spermatogenesis in rats. J Ethnopharmacol 2006; 103: 448-454.

12. Gonzales GF, Nieto J, Rubio J, Gasco M. Effect of Black Maca (Lepidium meyenii) on one spermatogenic cycle in rats. Andrologia. 2006; 38: 166-172.

13. Yucra S, Gasco M, Rubio J, Nieto J, Gonzales GF. Effect of different fractions from hydroalcoholic extract of Black Maca (Lepidium meyenii) on testicular function in adult male rats. Fertil Steril. 2008; 89 (5 Suppl):1461-1467.

14. Gasco M, Aguilar JD, Gonzales GF. Effect of chronic treatment with three varieties of Lepidium meyenii (Maca) on reproductive parameters and DNA quantification in adult male rats. Andrologia. 2007;39:151-158.

15. Gasco M, Villegas L, Villegas L, Rubio J, Gonzales GF. Dose-response effect of Red Maca (Lepidium meyenii) on benign prostatic hyperplasia induced by testosterone enanthate. Phytomedicine. 2007a;14:460-464.

16. Rubio J, Riqueros MI, Gasco M, Yucra S, Miranda S, Gonzales GF. Lepidium meyenii (Maca) reversed the lead acetate induced-Damage on reproductive function in male rats. Food Chem Toxicol. 2006a;44:1114-1122
17. Rubio J, Dang H, Gong M, Liu X, Chen S-L, Gonzales GF. Aqueous and hydroalcoholic extracts of Black Maca (Lepidium meyenii) improve scopolamineinduced memory impairment in mice. Food and Chemical Toxicology. 2007; 45:1882-1890.

18. Gonzales GF, Miranda S, Nieto J, Fernandez G, Yucra $\mathrm{S}$, Rubio S, et al. Red maca (Lepidium meyenii) reduced prostate size in rats. Reprod Biol Endocrinol 2005; $3(1): 5$

19. Gonzales GF, Vásquez V, Rodríguez D, Maldonado C, Mormontoy J, Portella J, et al. Effect of two different extracts of red maca in male rats with testosteroneinduced prostatic hyperplasia. Asian J Androl. 2007;9:245-251.

20. Gonzales GF, Gasco M, Malheiros-Pereira A, Gonzales-Castañeda C. Antagonistic effect of Lepidium meyenii (red maca) on prostatic hyperplasia in adult mice. Andrologia. 2008;40: 179-185.

21. Gonzales GF, Valerio LG Jr. Medicinal Plants from Peru: A review of plants as potential agents against cancer. Anti-Cancer Agents in Medicinal Chemistry. 2006; 6: 429-444.

22. Afssa - $\mathrm{N}^{\circ}$ 2008-SA-0011, ligada a $\mathrm{N}^{\circ}$ 2007-SA-0033. De la Agencia Francesa de Seguridad de los Alimentos relativo a la evaluación de los complementos de información concernientes al empleo del polvo de raíz de maca, comercializada tal cual o entrando en la composición de complementos alimentarios y alimentos corrientes. Maisons-Alfort, el 2 de Julio 2008

23. AFSSA. From the French Agency of Sanitary Security on foods relative to the risk assessment for health by consuming pulverized maca roots or as alimentary supplement. Afssa-Saisine 2004-SA-0155. 2004:1-3.

24. Gonzales GF, Gonzales-Castañeda C. The Methyltetrahydro-b-Carbolines in Maca (Lepidium meyenii). Evid. Complem. Altern. Med. 2009; 6:315-6.

25. Valentová K, Stejskal D, Bartek J, Dvorácková S, Kren $\mathrm{V}$, Ulrichová J, et al. Maca (Lepidium meyenii) and yacon (Smallanthus sonchifolius) in combination with silymarin as food supplements: in vivo safety assessment. Food Chem Toxicol. 2008 ;46:1006-1013

26. Gonzales GF, Córdova A, Gonzales C, Chung A, Vega $K$, Villena A. Lepidium meyenii (Maca) increased semen parameters in adult men. Asian Journal of Andrology. 2001; 3: 301-303 .

27. Gonzales GF, Cordova A, Vega K, Chung A, Villena A, Gonez C, et al. Effect of Lepidium meyenii (MACA) on sexual desire and its absent relationship with serum 
testosterone levels in adult healthy men. Andrologia 2002; 34:367-372.

28. Gonzales GF, Córdova A, Vega K, Chung A, Villena A: Effect of Lepidium meyenii (maca), a root with aphrodisiac and fertility-enhancing properties, on serum reproductive hormone levels in adult healthy men. J Endocrinol 2003; 176: 163-168.

29. Ronceros G, Ramos W, Garmendia F, Arroyo J, Gutierrez J. Eficacia de la maca fresca (Lepidium meyenii Walp) en el incremento del rendimiento físico de deportistas en altura. Anal. Fac. Med. 2005; 66: 269273.

30. Brooks NA, Wilcox G, Walker KZ, Ashton JF, Cox MB, Stojanovska L. Beneficial effects of Lepidium meyenii (Maca) on psychological symptoms and measures of sexual dysfunction in postmenopausal women are not related to estrogen or androgen content. Menopause. 2008;15:1157-1162.

31. Meissner HO, Kapczynski W, Mscisz A, Lutomski J. Use of gelatinized maca (Lepidium peruvianum) in early post-menopausal women- a pilot study. International Journal of Biomedical Science. 2005; 1: $33-45$

32. Dording CM, Fisher L, Papakostas G, Farabaugh A, Sonawalla S, Fava M, et al. A double-blind, randomized, pilot dose-finding study of maca root (L. meyenii) for the management of SSRI-induced sexual dysfunction. CNS Neurosci Ther. 2008;14:182-191.

33. Zenico T, Cicero AF, Valmorri L, Mercuriali M, Bercovich E. Subjective effects of Lepidium meyenii (Maca) extract on well-being and sexual performances in patients with mild erectile dysfunction: a randomised, double-blind clinical trial. Andrologia. 2009;41:95-99

34. Mehta K, Gala J, Bhasale S, Naik S, Modak M, Thakur $\mathrm{H}$, et al. Comparison of glucosamine sulfate and a polyherbal supplement for the relief of osteoarthritis of the knee: a randomized controlled trial [ISRCTN25438351]. BMC Complement Altern Med 2007; 7:34.

35. Stone M, Ibarra A, Roller M, Zangara A, Stevenson E. A pilot investigation into the effect of maca supplementation on physical activity and sexual desire in sportmen. J Ethnopharmacol. 2009;126:574-576.

36. INEI. Censo Nacional de Población y Vivienda Perú 2007. INEI:Lima 2007.

37. Alonso J, Prieto L, Antó JM. The Spanish version of the SF-36 health survey - A measure of clinical outcomes. [La versión española del "SF-36 Health
Survey" (Cuestionario de Salud SF-36): Un instrumento para la medida de los resultados clínicos] Med Clin (Barc) 1995; 104: 771-776

38. León-Velarde F, Maggiorini M, Reeves JT, Aldashev A, Asmas I, Bernardi L, et al. (2005) Consensus statement on chronic and subacute high altitude diseases. High Alt Med Biol. 6:147-157.

39. Albertsson DM, Mellström D, Petersson C, Eggertsen R. Validation of a 4-item score predicting hip fracture and mortality risk among elderly women. Ann Fam Med. 2007;5:48-56

40. Vilagut G, Ferrer M, Rajmil L, Rebollo P, PermanyerMiralda G, Quintana JM, et al. El cuestionario de salud SF-36 español: una década de experiencia y nuevos desarrollos. Gac. Sanit 2005; 19: 135-150.

41. Rentero ML, Carbonell C, Casillas M, González Béjar M, Berenguer R. Risk Factors for Osteoporosis and Fractures in Postmenopausal Women Between 50 and 65 Years of Age in a Primary Care Setting in Spain: A Questionnaire. The Open Rheumatology Journal 2008; 2:58-63

42. Gonzales GF, Tapia V, Gasco M, Gonzales-Castañeda C. Serum Testosterone levels and score of Chronic Mountain Sickness in Peruvian men natives at $4340 \mathrm{~m}$. Andrologia 2010. in press

43. León J. The maca (Lepidium meyenii). A little known food plant of Perú. Economic Botany 1964; 18: 122127.

44. Valentova K, Urichova J. Smallanthus sonchifolius and Lepidium meyenii - prospective andean crops for the prevention of chronic diseases. Biomed Papers 2003; 147:119-130.

45. Canales M, Aguilar J, Prada A, Marcelo A, Huaman C, Carvajal L: Nutritional evaluation of Lepidium meyenii (Maca) in albino mice and their descendants [in spanish]. Arch Latinoam Nutr 2000; 50: 126-133.

46. Ruiz-Luna AC, Salazar S, Aspajo NJ, Rubio J, Gasco M, Gonzales GF. Lepidium meyenii (Maca) increases litter size in normal adult female mice. Reproductive Biology and Endocrinology 2005; 3(1):16

47. Rubio J, Caldas M, Dávila S, Gasco M, Gonzales GF. Effect of three different cultivars of Lepidium meyenii (Maca) on learning and depression in ovariectomized mice. BMC Complementary and Alternative Medicine 2006, 6:23.

48. Wang Z, Yang J, Wang G, Bian L. [Influence of Lepidium meyenii walp on lipid and bone mass in ovariectomized rats]. Wei Sheng Yan Jiu. 2009;38:4202, 425. Chinese. 
49. Zhang Y, Yu L, Ao M, Jin W: Effect of ethanol extract of Lepidium meyenii Walp. on osteoporosis in ovariectomized rat. J Ethnopharmacol 2006; 105:274279.

50. Gonzales GF, Gasco M, Tapia V, Gonzales-Castañeda C. High serum testosterone levels are associated with excessive erythrocytosis of chronic mountain sickness in men. Am J Physiol Endocrinol Metab. 2009;296:E1319-E1325.

51. Bogani P, Simonini F, Iriti M, Rossoni M, Faoro F, Poletti A, et al. Lepidium meyenii (Maca) does not exert direct androgenic activities. J Ethnopharmacol 2006; 104: 415-417.

52. Giannini EG, Testa R, Savarino V. Liver enzyme alteration: a guide for clinicians. CMAJ. 2005;172:367379. Review.

53. Li G, Ammermann U, Quiros CF. Glucosinolate contents in maca (Lepidium peruvianum chacon) seeds, sprouts, mature plants and several derived commercial products. Economic Botany 2001; 55: 255-262.

54. Piacente S, Carbone V, Plaza A y col. Investigation of the tuber constituents of maca (Lepidium meyenii Walp). J Agric Food Chem 2002; 50: 5621-5625.

55. Fahey JW, Zalcmann AT, Taladay P. The chemical diversity and distribution of glucosinolates and isothiocyanates among plants. Phytochemistry 2001; 56:5-51.

56. Matusheski NV, Juvik JA, Jeffery EH. Heating decreases epithiospecifier protein activity and increases sulforaphane formation in broccoli. Phytochemistry 2004;65:1273-1281. 